Borneo Journal of Sciences \& Technology, 3(2): 70-75

DOI: http://doi.org/10.3570/bjost.2021.3.2-12

e-ISSN: 2672-7439

(C) 2018, UCTS Publisher.

Submitted: $19^{\text {th }}$ March 2021

Accepted: $09^{\text {th }}$ June 2021

Published: $31^{\text {st }}$ July 2021

\title{
Magnetic Sugarcane Bagasse Paper via Radiation Method - A Short Review
}

\author{
Annur Azlin Azmi and *Siti Amira Othman \\ Faculty of Applied Sciences and Technology, Universiti Tun Hussein Onn Malaysia (UTHM), \\ 84600, Pagoh, Johor, Malaysia.
}

\begin{abstract}
The global demand for wood fibre has increased due to the increasing population and new applications throughout the world. To supplement the limited wood fibre resources, non-wood fibres, especially sugarcane bagasse, have been introduced as alternatives in paper-based industries. This study addresses the analysis of magnetic sugarcane bagasse materials as substitute fibres in papermaking. Paper is generally made with cellulose fibre which has some specific educational, packaging and cleaning purposes. Sugarcane bagasse (Saccarhum officinarum) is a remaining residue left broken for sugar extraction. It is considerably popular for its cellulose, holocellulose, alpha-cellulose, and lignin that far more convenient than wood fibres. Meanwhile, demands for magnetic material in magnetic papermaking production have increased due to its excellent mechanical characteristics, low cost, and recyclability. The magnetic paper shows some superiority in properties such as renewable use and folding resistance. The introduction of filler in this study is to alter the paper properties such as texture, opacity, brightness, dimensional stability, ink absorbency, and overall printability. Nowadays, the requirement for fillers is to provide explicit upgrades to the quality of the sheets. Thus, a cobalt ferrite $\left(\mathrm{CoFe}_{2} \mathrm{O}_{4}\right)$ magnet as a filler can enhance the paper's properties. Cobalt ferrite is a hard-magnetic material with distinct properties such as good mechanical hardness and chemical stability. Therefore it is a much more suitable material for magnetic paper production. The integrity of the paper may decrease due to the presence of bacteria and fungi. Therefore, to increase the paper's integrity, the irradiation process by using gamma-ray can be done to the paper to avoid fungi and bacteria that can degrade the quality of the paper caused by spots and stains.
\end{abstract}

Keywords: Magnetic, Sugarcane Bagasse, Paper, Radiation

\section{INTRODUCTION}

Paper is the materials that have been used entirely for writing and packaging. The Chinese, Cai Lun was the person who made a paper sheet of about 105 CE. Paper is a thin material produced by pressing the moist fibre together and then drying it into flexible sheets. Paper has many uses, such as writing, printing, packaging, and several hygiene products in many industries and construction processes and even as a food ingredient. Also, paper can be made from wood and non-wood material such as fibre from bagasse, banana fibre and pineapple leaves. [1]. Generally, the paper is widely made with a fibre called cellulose fibres with some specific features. As nowadays, paper essentially comprises wood, which is the primary material for producing global pulp and paper. This phenomenon can make a significant contribution to the depletion of natural forests that have harmed the environment. Therefore, bagasse is a non-wood material that is closely related to the wood element. Apart from that, it has a higher moisture content. It is also considerably popular as a supply of the production of the paper industry [3].

Bagasse is produced of non-wood fibre; therefore, it can be used as a substitute in the papermaking industry for the future. Sugarcane bagasse is an abundant lignocellulosic waste usually cultivated in open sugarcane processing countries. The sugar cane stalk includes two parts, the inner pit usually contains utmost sucrose and the outer rind containing lignocellulosic fibres. Throughout sugar processing, the sugar cane stalk is shredded in the process of extracting sucrose. This method generates a significant quantity of sugarcane bagasse residue, including pith fibres and crushed rind [15]. In addition, to improve the quality and efficiency of paper production, the addition of other material on paper preparation was important. The use of filler in wet and chemistry and paper retention aid requires a certain amount of understanding in paper production chemistry. This will lead to better paper

Corresponding Author: Siti Amira Othman. Affiliation, Faculty of Applied Sciences and Technology, Universiti Tun Hussein

Onn Malaysia (UTHM), Email: sitiamira@uthm.edu.my 
formation retain as much as filler. For more than two centuries, the filler has been used as an additive to enhance paper quality such as brightness, opacity, smoothness, and printability, reducing production costs [16].

This study also provides many benefits, especially to paper industries, to create paper from sugarcane bagasse to provide alternative ways to reduce environmental problems and cost-effectiveness. Sugarcane bagasse is easier to get, simple, and low cost compared to making wood fibre as paper. The manufacture of sugarcane bagasse paper may help minimize deforestation in the development of paper, which also contributes to biodegradable, biocompatible, and eco-friendly paper utilizing non-wood fibre. This would help the industry to develop sustainable technology in the current economy and environmental order. The introduction of magnetic material inside the paper that acts as a filler to improve and enhance the paper's quality and strength is investigated in this study.

\section{LITERATURE REVIEW}

\section{Sugarcane Bagasse as Paper}

Sugarcane bagasse is known as (Saccarhum officinarum) is a remaining residue composed in an enormous amount. This heterogeneous fiber residue remaining behind by sugarcane stalks broken for sugar extraction. Bagasse is closely related to the wood element; apart from that, it has a higher moisture content. It is also considerably popular as a supply of the production of the paper industry [3].

\section{Magnetic Material as Filler in Paper Production}

Nowadays, the interest in magnetics paper has increased due to the hidden potential in a broad application [7]. Magnetite $\left(\mathrm{Fe}_{3} \mathrm{O}_{4}\right)$ is one of the most commonly used magnetic materials in magnetic papermaking production. Yet, Cobalt ferrite has an excellent mechanical characteristic; thus, it is more ideal for paper production [11]. The introduction of filler can improve the quality of the paper performances such as texture, opacity, and physical [8]. Besides that, the main reason associated with magnetic material is because magnetic paper exhibits some supercities such as softness, renewable use, and folding resistance [4].

\section{Radiation Exposure on Magnetic Paper Production}

Besides, the paper cellulose fibres may also be degraded by microorganisms and pests that may affect their integrity. This damage can be used by the chemicals produced by the processes of metabolic fungi while using cellulose as a source of nutrients and pigmenting mycelium and spores. The enzymes could then be produced by the fungi that catalyzed the cellulose hydrolysis. The presence of these pillows and bacteria in the paper also poses a health risk that may affect the disinfection. The best way is irradiation for mass cleansing toward bacteria, microorganisms, and insects. As a function of ionizing radiation, gamma rays have been used as radiation control for paper processing. Gamma rays have higher penetrating power compared to alpha and beta. As with other disinfectant treatments, irradiation has the preferred perspective that it does not leave the unsafe building on the material handled [6].

In the production of magnetic sugarcane bagasse paper, the primary materials are sugarcane bagasse and cobalt ferrite $\left(\mathrm{CoFe}_{2} \mathrm{O}_{4}\right)$ magnets. In addition to the usage of sugarcane bagasse and cobalt ferrite magnet, other components used in the study included Sodium Hydroxide $(\mathrm{NaOH})$ [10]. For radiation penetration of the magnetic sugarcane bagasse paper, Cobalt-60 Gamma cell 220 Source was used to radiate the paper because gamma radiation has a higher power of penetration through paper instead of alpha and gamma radiation which has lower power of penetration. This gamma radiation needs to be used in different doses to show the different effects on the paper and the experiment's output [7].

\section{Lumen-loading process}

In the production of magnetic sugarcane bagasse paper, the primary materials are $10-15 \mathrm{~g}$ sugarcane bagasse, 15 - $20 \% \mathrm{NaOH}$ and $7.5 \mathrm{~g}$ cobalt ferrite. Therefore, sugarcane bagasse pulp samples and magnetic material will undergo the lumen-loading process [16]. The sugarcane bagasse paper was collected from the juice shop after being crushed using a hand crushing machine. After that, the collected sugarcane bagasse was allowed to dry under sunlight for $2-3$ days. The sugarcane bagasse was cut into $100-200 \mathrm{~mm}$ each size and weighed $15 \mathrm{~g}-20 \mathrm{~g}$ before mixed with $10 \%-15 \%$ Sodium Hydroxide $(\mathrm{NaOH})$ solution. Sugarcane bagasse was boiled with Sodium Hydroxide $(\mathrm{NaOH})$ solution for 60 minutes. Then, washed again with distilled water until $\mathrm{pH} 7$ was maintained. The fibres were then dried at room temperature for 48 hours, followed by oven drying at $100^{\circ} \mathrm{C}$ for 6 hours [10]. The sugarcane bagasse undergoes a beating process by blending it with $400 \mathrm{ml}$ distilled water until it becomes pulp about 7- 10 minutes. After the beating process, the pulp was suspense with filler, cobalt ferrite magnet then was put into mold and deckle. The deckle was removed, and the paper was ready to dry under the sunlight for 2 3 days. Magnetics sugarcane bagasse paper was prepared. 


\section{Magnetic Sugarcane Bagasse Paper Via Radiation Method - A Short Review}

\section{Characterization of Magnetic Paper}

The magnetic sugarcane bagasse paper samples were observed pre-and post- radiation to identify and observe the changes in the paper [7]. The structure, properties, and characteristics of the magnetic sugarcane bagasse paper sample were identified by using Scanning Electron Microscope (SEM) [8], Fourier Transformation Infrared Spectroscopy (FTIR), Tearing Tester Machine and $\mathrm{pH}$ meter. SEM was used to obtain the surface topography and composition [8], FTIR is to know the chemical bonding \& functional group, tearing tester machine is to study the tearing strength of the paper while $\mathrm{pH}$ meter to determine the acidity and alkalinity of the paper.

\section{Effect of Texture, Colour, and Bulk Density}

The table shows that the colour of unirradiated sugarcane bagasse was off-white, which remains unchanged on gamma irradiation exposure up to 100 $\mathrm{kGy}$. When the irradiation dose rises to $500 \mathrm{kGy}$, the colour transforms to yellow while brown at $2000 \mathrm{kGy}$. At $500 \mathrm{kGy}$ doses, the unirradiated sugarcane bagasse texture was hard and then fluffy when 500kGy and $1000 \mathrm{kGy}$.While, at larger doses, 2000kGy, it was entirely disintegrated into a powder mixture [10]. Besides that, the bulk density of unirradiated sugar cane bagasse was quantified at $83 \mathrm{~kg} / \mathrm{m}^{3}$, which modify to $154 \mathrm{~kg} / \mathrm{m}^{3}$ at $2000 \mathrm{kGy}$ [10].

Table 1: Gamma irradiation effect on colour, texture, and bulk density of sugarcane bagasse [10].

\begin{tabular}{|c|c|c|c|}
\hline Dose, $(\mathrm{kGy})$ & Colour & Texture & $\begin{array}{c}\text { Bulk Density } \\
(\mathrm{kg} / \mathrm{m})\end{array}$ \\
\hline Unirradiated & Off-white & Hard & 83 \\
\hline 100 & Off-white & Hard & 81 \\
\hline 500 & Yellow & Fluffy & 86 \\
\hline 1000 & Yellow & Fluffy & 95 \\
\hline 2000 & Brown & Powder & 154 \\
\hline
\end{tabular}

Even though [16] state that the utilization of filler in the chemistry and retention aid during the papermaking will lead to a better paper formation as it improves the paper properties such as opacity, brightness, smoothness, and printability [16]. Yet, in combination with cobalt ferrite to form a magnetic paper, the magnetic particles collected on the surface of the fibres shows reducing in ISO brightness and tensile index of customized magnetic papers. As shown in Figure 1, the brightness of the paper is reduced due to the attributable of the black colour of cobalt ferrite nanoparticles [12]. Also, there is research shows a typical finding by using unbleached kenaf pulp and magnetite nanoparticles [5].

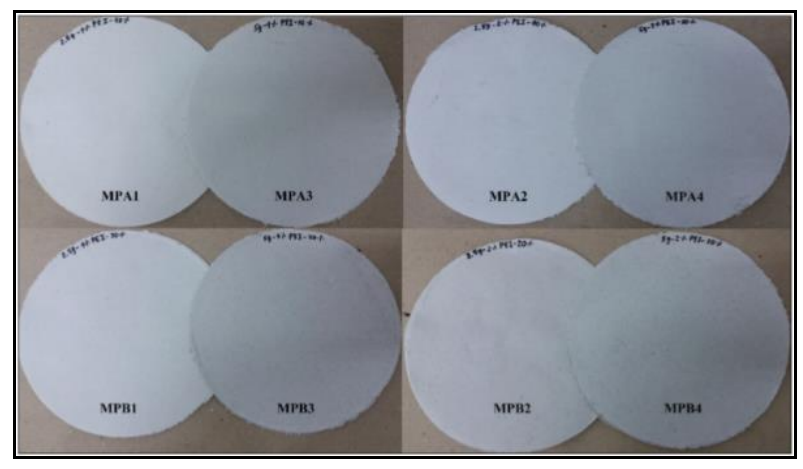

Figure 1: Effect of different temperature of reaction to RCO \% of epoxidation [12].

\section{Effect of Chemical Constituents}

As shown in Figure 2, the irradiated sugarcane bagasse does not show much change in lignin, ash, and moisture content. The hemicellulose component of sugarcane bagasse gets most affected on radiation exposure, which is reduced on $100 \mathrm{kGy}$ exposure and further decreased to at $2000 \mathrm{kGy}$ dose. The cellulose content of irradiated and unirradiated bagasse samples presents with no significant change in the cellulose content up to 100 kGy exposure. However, on further exposure to 500 and $1000 \mathrm{kGy}$, the cellulose content decreases, respectively. Further exposure of bagasse to $2000 \mathrm{kGy}$ dose, the cellulose content reduced more [10].

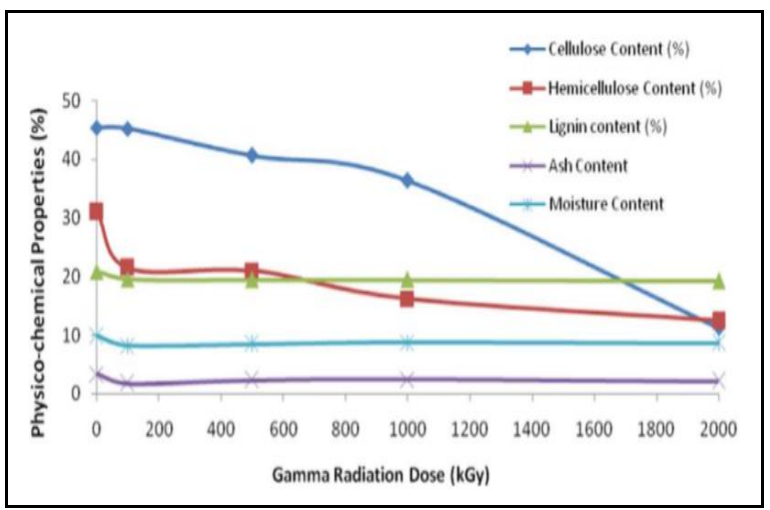

Figure 2: Effect of exposure of $\gamma$-radiation on the physico-chemical properties of sugarcane bagasse [10].

Also, Figure 3 shows the radiation effect on the cellulose in the three essays presented an exponential trend with the provided absorbed dose. It can be considered that the cellulose has been insulated by lignin and hemicellulose [14]. 


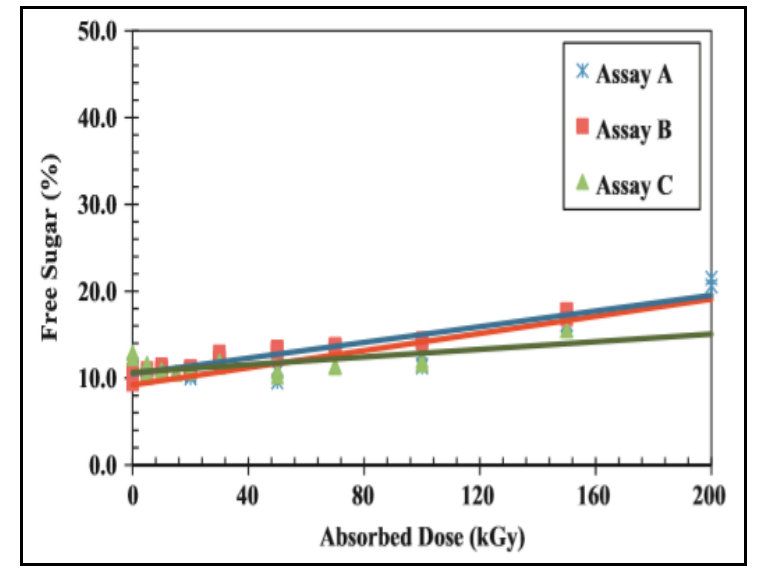

Figure 3: Decomposition of cellulose in sugarcane bagasse samples from assays A, B, C of the absorbed dose [14].

Celluloses are the core elements of secondary layers in lignocellulose fibres on the cell wall. These celluloses are prevalent in the surface layer, for instance, the outer layer of the fibres, where these polymers can act as adhesives to build a strong bond between the individual fibres in the three-dimensional web of a piece of paper [3]. Such high cellulose content thereby increases the quality of paper produced Since the cellulose shows no significant differences in the cellulose content either unirradiated or irradiated. This helps to prove that sugarcane bagasse another alternative that can be used in papermaking [2].

\section{Effect on Morphology}

Figure 4 shows the morphology of bagasse irradiated with gamma-ray of $2000 \mathrm{kGy}$ by using SEM. It shows the existence of pores in bagasse lignocellulosic components. Thus, it is evident from the micrographs that the pre-treatment exposure of gamma irradiation of sugarcane bagasse opens cellulose, making cellulose more accessible to acids and hydrolytic enzymes [10].

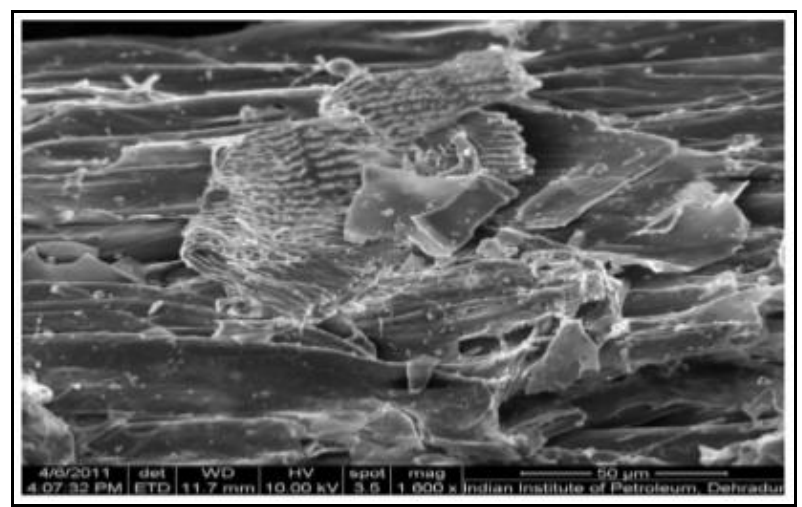

Figure 4: Gamma irradiated sugarcane bagasse by SEM image at $2000 \mathrm{kGy}$ [10].

\section{Effect on pH Reading on Bagasse Paper}

In the research by [11], As shown in Figure 5, after the chemical treatment of $\mathrm{NaOH}$ took place, the color of the treated bagasse fibres changed as the sugarcane bagasse fibres turn into yellowish. This may due to the removal of the impurities that exist on the surface of the fibre. Besides, it may be attributed to the elimination of the waxy layer and impurities from the surface of the fibre.

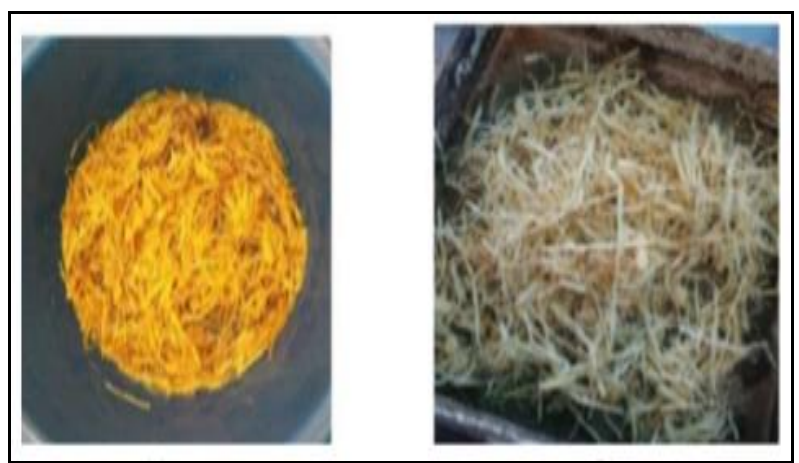

Figure 5: Bagasse fibre after treated in solution after 1 hour (a) $5 \% \mathrm{NaOH}$ treated, (b) 5\% HCL treated [11].

\section{FTIR Analysis}

The FTIR spectra of cellulose fibres from magnetics sugarcane bagasse are similar to this research as they used magnetic in the paper. According to [12], the FTIR of cellulose fibres from spectra were obtained to investigate the surface functional groups of silicacoated cobalt ferrite nanoparticles as well as of unmodified and modified fibres. Figure 6 shows the spectrum of $\mathrm{CoFe}_{2} \mathrm{O}_{4}-\mathrm{SiO}_{2}$ nanoparticles presents absorption bands at 555 and $432 \mathrm{~cm}-1$ associated with the stretching vibration of $\mathrm{Fe}-\mathrm{O}$ bond in the tetrahedral site and the bending vibration of $\mathrm{Co}-\mathrm{O}$ bond in the octahedral site, respectively. The band at $3363 \mathrm{~cm}^{-1}$ corresponds to the O.H. bond vibration, and the bands lie between 3363 and $1643 \mathrm{~cm}^{-1}$ are due to the $\mathrm{H}-\mathrm{O}-\mathrm{H}$ bond bending vibration. These bands are related to adsorbed water molecules by magnetic nanoparticles. Moreover, this spectrum shows the vibration peaks of silica matrix at $1087,948,879$, and $786 \mathrm{~cm}^{-1}$, that are assigned to $\mathrm{Si}-\mathrm{O}$ bonds vibration of the $\mathrm{SiO} 4$ tetrahedron and $\mathrm{Si}-\mathrm{O}-\mathrm{Si}$ asymmetric stretching vibration, $\mathrm{Si}-\mathrm{O}-\mathrm{Fe}$ and $\mathrm{Si}-\mathrm{O}-\mathrm{H}$ stretching vibration, $\mathrm{Si}-\mathrm{O}-\mathrm{Si}$ symmetric stretching vibration and vibration mode of the ring structure of $\mathrm{SiO}_{2}$ tetrahedral, respectively. The $\mathrm{Si}-\mathrm{O}-\mathrm{Fe}$ vibrations are due to the interaction between $\mathrm{Fe}^{3}$ ions and the silica matrix [12].

The presence of these vibration peaks indicates the formation of silica matrix generating new $\mathrm{Fe}-\mathrm{O}-\mathrm{Si}$ bonds, where $\mathrm{Fe}-\mathrm{O}-\mathrm{H}$ groups on nanoparticles surface 


\section{Magnetic Sugarcane Bagasse Paper Via Radiation Method - A Short Review}

are replaced by $\mathrm{Fe}-\mathrm{O}-\mathrm{SiO}_{3}$. A spectrum of $\mathrm{UMF}$ sample shows absorption bands at 3325, 2885, 1620, 1026, and $655 \mathrm{~cm}-1$, that correspond to $\mathrm{O}-\mathrm{H}$ linked shearing (polysaccharides), $\mathrm{C}-\mathrm{H}$ symmetrical stretching (polysaccharides), $\mathrm{C}=\mathrm{O}$ unconjugated stretching (xylans), C-O-C asymmetrical stretching (cellulose) and C-O.H. out of plane bending (cellulose), respectively. Besides, absorption bands between 1650 and $1620 \mathrm{~cm}^{-1}$ result from the O.H. bond vibration of adsorbed water by fibres. The spectra of MF1, MF2, MF3, and MF4 samples present absorption bands of magnetic particles and bleached fibres. Therefore, it signifies the effective interaction cellulose network of fibres and cobalt ferrite nanoparticles for papermaking [12].

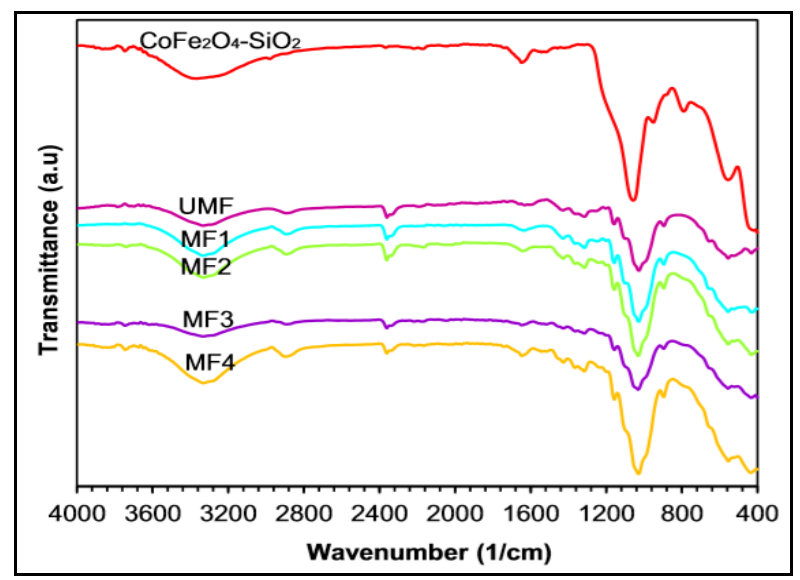

Figure 6: FTIR spectra of silica-coated cobalt ferrite nanoparticles as well as modified fibers and unmodified fibers [12]

\section{Suitability of Magnetic Material on Sugarcane Bagasse Paper}

Sugarcane bagasse is likely attractive to produce magnetic paper. According to [12], Magnetite $\left(\mathrm{Fe}_{3} \mathrm{O}_{4}\right)$ is usually commonly used in the production of magnetic paper. Since cobalt ferrite $\left(\mathrm{CoFe}_{2} \mathrm{O}_{4}\right)$ controls the content, which is more vital than magnetite thus is more suitable as magnetic paper. Cobalt ferrite is recognized as a hard-magnetic substance with distinctive properties like heavy magneto-crystalline anisotropy, broad magneto-optical coefficients at room temperature, high curie temperature, moderate saturation magnetization, reasonable mechanical toughness, and chemical stability. Therefore, it can be concluded that the incorporation of sugarcane bagasse to be coated with magnetic material is suitable for papermaking [12].

\section{CONCLUSIONS}

In conclusion, this magnetic sugarcane bagasse paper shows better structure and strength. Based on the characterization and properties written by all researchers that work similarly in this study, this innovation should work just like any other paper available in this world. Yet, due to its innovation, it provides many advantages to society. Thus it can be commercialized for the paper industry in the future.

\section{ACKNOWLEDGMENTS}

The authors would like to thank the Faculty of Applied Sciences and Technology, Universiti Tun Hussein Onn Malaysia, for making the research possible.

\section{REFERENCES}

[1] Al-Sulaimani, K., and Priy Brat, D. 2017. Production Of Handmade Papers From Sugarcane Bagasse And Banana Fibers In Oman. International Journal of Students Research in Technology and Management, 5(3), 16-20.

[2] Aremu, M. O., Rafiu M.A., and Adedeji, K.K., 2015. Pulp and Paper Production from Nigerian Pineapple Leaves and Corn straw as Substitute to Wood Source, 2(4),1180-1188.

[3] Azhar, S S., Suhardy, D., Farhana, D. M.Y., Farizul Hafiz, K., and Harbant, S. 2007. Isolation and Characterization of Pulp from Sugarcane Bagasse and Rice Straw. Journal of Material Engineering 4, 109-113.

[4] Calvo, S., Arias, N. P., Giraldo, O., RosalesRivera, A., and Moscoso, O. 2012. Thermal and magnetic behaviour of Angustifolia Kunth bamboo fibers covered with $\mathrm{Fe}_{3} \mathrm{O}$ particles. Physica B: Condensed Matter, 407(16), 32673270 .

[5] Chia, C. H., Duong, T. D., Nguyen, K. L., and Zakaria, S. 2007. Thermodynamic aspects of sorption of $\mathrm{Fe} 2+$ onto unbleached kraft fibers. Journals of Colloid and Interface Science, 307(1), 29-33.

[6] Coppola, F., Fiorillo, F., Modelli, A., Montanari, M., and Vandini, M. 2018. Effects of gamma-ray treatment on paper. Polymer Degradation and Stability, 150, 25-30.

[7] D’Almeida, M.L.O., Barbosa, P.de S.M., Boaratti, M. F. G. and Borrely, S. I. 2009. Radiation effects on the integrity of paper. Radiation Physics and Chemistry, 78(7-8),489492.

[8] Gao, D., Ma, J., Li, Z., and Liu, J. 2014. Preparation and characterization of a new white magnetic paper. Materials letters,137,487-490.

[9] Gill, R. A. 1995. Fillers for papermaking. Applications of Wet-End Paper Chemistry, 5475. 
[10] Kapoor K., Neelima, G., Diwanb R.K., Lalit V., and Ajay K. T. 2019. Study the Effect Of Gamma Radiation Pretreatment of Sugarcane Bagasse on Its Physcio-Chemical Morphological and Structural Properties. Radiation Physics and Chemistry 141 (2017), 190-195.

[11] Nursuzailina Mohamed Sutan, Siti Masjida Mazlan, Siti Noor Linda Taib, Delsye Teo, Ching Lee, Alsidqi Hassan, Siti Kudnie Sahari, Khairul Anwar Mohamed Said, and Habibu Rahman Sobuz. 2018. Biomass Morphology Subjected to Different Chemical Treatment. E3S Web of Conferences 34(1), 18.

[12] Oscar, H. P., Emma, C. S., Adriana, P. H., Jorge, H. S. and, German, C. Q. 2020. Magnetic paper from sugarcane bagasse fibers modified with cobalt ferrite nanoparticles. Cellulose 27, 39033918 .
[13] Sibaly, S., and Jeetah, P. 2017. Production of paper from pineapple leaves. Journal of Environmental Chemical Engineering, 5(2017), 5978- 5986.

[14] Ribeiro, M. A., Oikawa, H., Mori, M. N., Napolitano, C. M. and Duarte, C. L. 2013. Degradation mechanism of polysaccharides on irradiated sugarcane bagasse. Radiat Phys Chem 84, 115-118

[15] Samariha A., and Khakifirooz, A. 2017. Application of NSSC pulping to sugarcane bagasse. BioResources 6(3), 3313-3323.

[16] Zakaria, S., Ong, B. H., and Van De Ven, T. G. M. 2004. Lumen Loading magnetic paper II: Mechanism and kinetics. Colloids and Surfaces A: Physicochemical and Engineering Aspects, 251(1-3), 31-36. 